\title{
Application \\ of the commensurability method for long-term forecasting of the highest summer floods on the Danube River at Bratislava
}

Borys Khrystiuk, Liudmyla Gorbachova (D)

Ukrainian Hydrometeorological Institute, 37 Prospekt Nauky, 03028 Kyiv, Ukraine, e-mail: gorbachova@uhmi.org.ua

Pavla Pekárová, Pavol Miklánek

Institute of Hydrology, Slovak Academy of Sciences

DOI: $10.26491 / \mathrm{mhwm} / 114482$

\footnotetext{
ABSTRACT. This paper reports the use of the commensurability method for long-term forecasting of the highest summer floods on the Danube River at Bratislava. Bratislava is the capital of the Slovak Republic, as well as its major administrative and industrial centre. In the past, Bratislava has suffered from dangerous floods. The highest floods have occurred most frequently in the summer. Consequently, long-term forecasting of summer floods on the Danube River at Bratislava has important scientific and practical significance. We used the dates of the highest summer floods for the period 1876-2018, as well as historical information about the highest summer floods that occurred before the beginning of regular hydrometric observations. The commensurability method supports prediction of various natural phenomena, including floods and other dangerous events. It is characterized by the simplicity of the calculations and minimum needs for input information. Four methods of forecasting were used: (1) the calculated value of commensurability; (2) the two-dimensional and three-dimensional graphs of commensurability; (3) the time intervals between floods that have occurred in the past; and (4) the number of commensurability equations with three components. The results indicate that the highest summer floods are likely to occur on the Danube at Bratislava in 2020, 2025 , and 2030.
}

KEYWORDS: Flood, long-term forecasting, Weng Wen-Bo method, commensurability. 


\section{INTRODUCTION}

The Danube River is closely linked to the economic, social, political, and spiritual spheres of public life in 19 European countries, which are wholly or partly located in its basin. It is the water transport artery connecting Central Europe with the Balkans, the Black Sea, and the Middle East (Pekárová et al. 2014). The mechanical energy of the streamflow is converted into electrical energy at 18 hydroelectric stations on the Danube River. The river is also a source of potable and non-potable water for the population, industry, and agriculture of all the Danube countries (Khrystyuk 2013). Despite the many benefits of the river, after heavy rainfall or intensive snowmelt in the basin, catastrophic floods occur periodically, with flooding of densely populated flood plains, leading to property damage and sometimes losses of human lives (Böhm, Wetzel 2006; Romanescu, Stoleriu 2010; Pekárová et al. 2013; Rohr 2013; Sonnlechner et al. 2013; Pekárová et al. 2014; Tenk, Dávid 2015; Blöschl et al. 2016). Therefore, research, modeling, and forecasting of the Danube runoff have scientific and practical importance.

The main or traditional methods of hydrological forecasting are statistical methods, such as correlation and regression analysis, etc., also known as simplified methods. Modern hydrological forecasting often uses a variety of mathematical models (WMO 2009). All these approaches are quantitative methods of forecasting. In general, for the Danube River basin, simplified methods and a stochastic approach have been used for long-term forecasting (for periods exceeding 10 days) (Pekárová et al. 2007; Khrystyuk 2014; Komma et al. 2017; Meissner et al. 2017). However, quantitative hydrological forecasts are not as reliable as they need to be. The development of prognostic systems that would allow accurate and reliable determination of flood hazards is an important, yet difficult task for hydrologic practice (Pekárová et al. 2013; Blöschl et al. 2016).

Along with quantitative forecasting methods, qualitative approaches have been developing (Hongyan et al. 2011; Su, Hu 2015; Peng et al. 2017). One of these approaches is the commensurability method, which the Chinese geophysicist Weng Wen-Bo proposed for long-term forecasting of various natural phenomena (Weng 1984). This method uses the dates on which extreme natural phenomena (earthquakes, floods, droughts, etc.) were observed. For this reason, it has been called the information method. Weng Wen-Bo's method is characterized by simplicity of calculation, graphical visualization, and the use of researcher intuition. The Weng Wen-Bo method was successfully used for forecasting the dates of several large earthquakes in China, Japan, and the USA; wet and dry years in the Songhua River Basin; and the floods in northeast China (Hongyan et al. 2011; Su, Hu 2015; Peng et al. 2017).

The objective of this paper is to use the Weng Wen-Bo information method for long-term forecasting of floods and determination of the most likely years in which these floods will occur on the Danube River at Bratislava.

\section{STUDY AREA AND DATA}

The Danube is the largest river in Western and Central Europe. The catchment area is $817,000 \mathrm{~km}^{2}$, and the river's length is $2,857 \mathrm{~km}$. The Danube basin is naturally divided into three parts by mountain ranges: Upper, Middle, and Lower Danube (Fig. 1). The Upper and Middle Danube are separated by the Alps and the Carpathians; the Middle and Lower Danube are separated by the Balkans and the Carpathians. Each major region of the Danube basin is under the influence of specific air masses. The Upper Danube is mainly influenced by the Atlantic and the Mediterranean air masses, the Middle Danube is under the influence of the Atlantic, continental, and Mediterranean

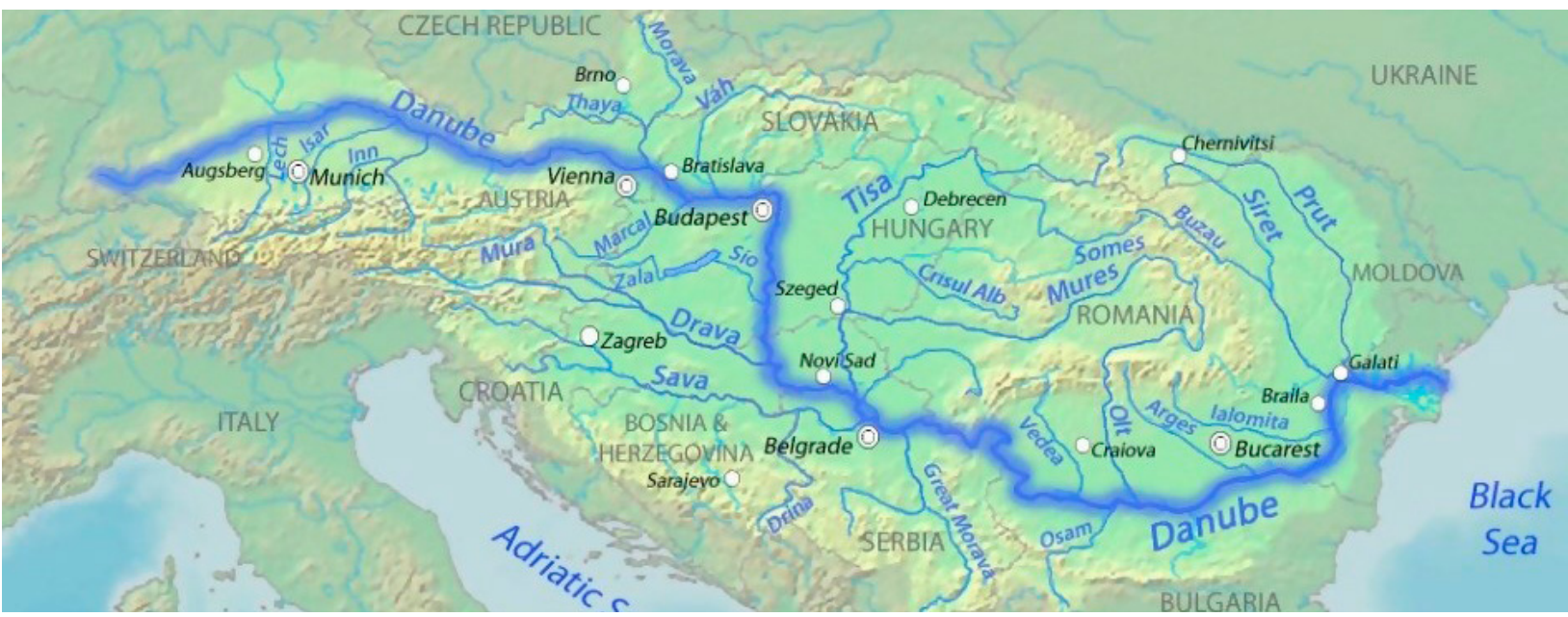

Fig. 1. The Danube River Basin

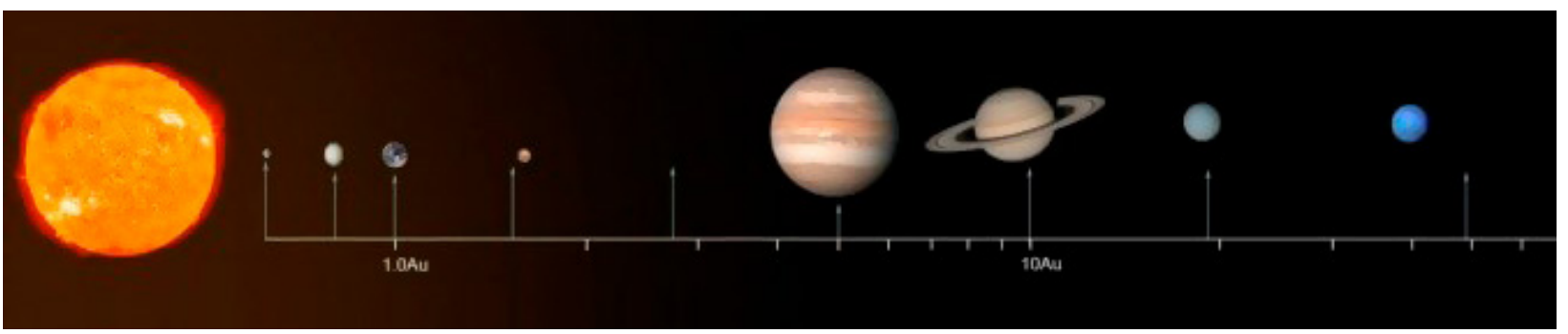

Fig. 2. Illustration of the Titius-Bode Law 
air masses, and the Lower Danube is mostly under the influence of continental air masses. The Danube River has a complex hydrological regime because of the varied atmospheric circulation and topographical relief in its basin. The Danube's runoff is formed mainly in its Upper part. In its Middle part additional runoff is contributed by melting snow in the Carpathians and the Balkans, and by rainfall. The Lower Danube is mainly an area of transient flow (Pekárová et al. 2008; Khrystyuk 2013; Pekárová et al. 2014)

Floods are not synchronous between individual parts of the Danube River Basin. Floods occur most frequently in June-August in the Upper Danube River Basin, in April in the Middle part, and April-May in the Lower part. So, depending on timing, the floods can be all water (in summer) or water and ice. In accordance with both archival data and data for the instrumental observation period, the highest floods occurred most frequently in the summer (Pekárová et al. 2014). Therefore, for our investigation, we used observation data from the gauging station at Bratislava, which represents the flood regime of the Upper Danube. This station has a long period of observation, beginning in 1876 . For this investigation we used observed data for summer floods from 1876 to 2018.

\section{METHODOLOGY}

The Danube River runoff has cyclical fluctuations. In our research we have shown that the river and its tributaries are characterized by consistent iteration of the wet and dry phases of cyclical fluctuations (Pekárová et al. 2006; Gorbachova, Khrystyuk 2014; Pekárová et al. 2014; Gorbachova 2015; Zabolotnia et al. 2019). Such fluctuations have different durations. The longer cycles of fluctuations sometimes include less prolonged alternations of wet and dry years. The presence of various cyclic fluctuations is conditioned by the influence of various factors, mechanisms, and principles that can be described by the combined effects of periodic and random factors, as well as by the characteristics of the river basin.

In 1766 the German physicist and mathematician I.D. Titius discovered that the distances of the solar system planets from the Sun $\left(R_{n}\right)$ (Fig. 2) obey a simple empirical rule:

$$
R_{n}=4+3 \cdot 2^{n}
$$

where $n=-\infty$ for the planet Mercury and $n=0$, $1,2 \ldots$ for the next planets.
By studying this astronomical rule, which is also called the Titius-Bode Law, Weng WenBo (1984) suggested that similar order is universal. Thus, various natural phenomena are subject to laws like the Titius-Bode Law. Equation (1) can be written as:

$\beta=\frac{\Delta R_{n+1}}{\Delta R_{n}}=\frac{R_{n+1}-R_{n}}{R_{n}-R_{n-1}}=\frac{3 \cdot 2^{n+1}-3 \cdot 2^{n}}{3 \cdot 2^{n}-3 \cdot 2^{n-1}}=2$

where $n=-\infty, 0,1,2 \ldots ; \beta$ is the value of commensurability for the solar system planets.

According to the hypothesis of Weng WenBo, the dates of various natural disasters have a periodicity, which is created by the cosmic influences. Weng Wen-Bo used the term commensurability, which was earlier proposed by Titius. Equation (2) brings to light the law of distribution of matter in a region of space. For the time domain, the commensurability $(\Delta X)$ can be expressed as (Su et al. 2016):

$$
\Delta X=\frac{X_{i+\Delta i}-X_{i-1}}{K}
$$

where $K$ is an integer $(1,2, \ldots) ; \mathrm{X}_{\mathrm{i}}$ is an element of the data set. If $K$ is equal to 1 , then $\Delta X$ is the period of the data set.

For long-term forecasting of extreme natural events the method of Weng Wen-Bo can be used in several ways. We used four methods of forecasting:

1. by the calculated value of commensurability;

2 . by the two-dimensional and three-dimensional graph of commensurability;

3. by the time intervals between floods that have occurred in the past;

4 . by the number of commensurability equations with three components.

The first method requires calculating the commensurability value from the array of dates on which the extreme events occurred, using equation (3). Forecasts are given in the form of points on the time axis, showing when the next event may occur, taking into account the forecast error.

The second method requires detecting the commensurability values in the array of dates for extreme events and the creation of two- and three-dimensional commensurability graphs.

These graphs are created by considering all possible combinations of values of commensurability.

Final graphics should have the following properties:

- account for the maximum possible observation period;
- include as many dates of extreme events as possible;

- contain periodicity and symmetry vertically and horizontally on two-dimensional graphs and on three sides of three-dimensional graphs;

- have an aesthetic appearance.

Forecasts employ the values of commensurability on the horizontal and vertical axes of the two-dimensional graph and three sides of three-dimensional commensurability graphs.

The third method is to determine the time intervals between the floods that have occurred in the past and the extrapolation of these time intervals for the future. This forecast can be visualized by creating a graph.

For the fourth method we need to draw up the commensurability equations with three components that will indicate the date of the upcoming extreme event:

$$
X_{i}+X_{j}-X_{k}=X_{l}
$$

where $\mathrm{X}_{l}, \mathrm{X}_{\rho}, \mathrm{X}_{k}, \mathrm{X}_{l}$ - the date array of the extreme events; $i, j, k, l=1,2, \ldots, n$-the integers; $n$ - the number of dates in the extreme events array.

Dates that have the largest number of such equations are the dates of a possible extreme event.

\section{RESULTS AND DISCUSSION}

At Bratislava, regular monitoring of the Danube River runoff began in 1876. During the period 1876-2018, fourteen of the highest summer floods were recorded. The maximum discharges of such floods were more than $8,050 \mathrm{~m}^{3} \mathrm{~s}^{-1}$ (Table 1). This value corresponds approximately to a discharge of $10 \%$ probability $\left(Q_{10 \%}=8,140 \mathrm{~m}^{3} \mathrm{~s}^{-1}\right)$.

\section{Forecasting results by the calculated value of commensurability}

Applying equation (3), we calculated the commensurability values of the highest summer floods that were observed on the Danube River at Bratislava in the period from 1876 to 2018 (Table 2). The value of commensurability $(\Delta X)$ is 2.60 years, the value of $K$ varies in the range $0-13$, and the forecast error is \pm 1 year. The value $\Delta X$ was determined by successive approximation, which minimized the error. We have applied the criteria $\Sigma \mid$ Error $\mid$ and $\Sigma$ (Error).

The results of these calculations determine the dates of the possible subsequent highest summer floods on the Danube River at Bratislava (Table 3). 
Table 1. The highest summer floods on the Danube River at Bratislava for the period 1876-2018

\begin{tabular}{|c|c|c|c|c|c|}
\hline No. & Year & Discharge $\left[\mathrm{m}^{3} \mathrm{~s}^{-1}\right]$ & No. & Year & Discharge $\left[\mathrm{m}^{3} \mathrm{~s}^{-1}\right]$ \\
\hline 1 & 1883 & 9,062 & 8 & 1965 & 9,224 \\
\hline 2 & 1890 & 8,548 & 9 & 1975 & 8,715 \\
\hline 3 & 1892 & 8,380 & 10 & 1991 & 9,430 \\
\hline 4 & 1897 & 10,140 & 11 & 2002 & 10,370 \\
\hline 5 & 1899 & 10,870 & 12 & 2009 & 8,242 \\
\hline 6 & 1920 & 8,616 & 13 & 2010 & 8,071 \\
\hline 7 & 1954 & 10,400 & 14 & 2013 & 10,640 \\
\hline
\end{tabular}

Table 2. Commensurability of the highest summer floods on the Danube River at Bratislava in the period from 1876 to 2018

\begin{tabular}{|c|c|c|c|c|c|}
\hline No. & Years $\left(X_{i}\right)$ & $\left(X_{i}-X_{i-1}\right)$ & $K$ & $K^{*} \Delta X$ & Error: $\left(X_{i}-X_{i-1}\right)-K^{*} \Delta X$ \\
\hline 1 & 1883 & & & & $-1(-0.8)$ \\
\hline 2 & 1890 & 7 & 3 & 8 & $-1(-0.6)$ \\
\hline 3 & 1892 & 2 & 1 & 3 & $0(-0.2)$ \\
\hline 4 & 1897 & 5 & 2 & 5 & $-1(-0.6)$ \\
\hline 5 & 1899 & 2 & 1 & 3 & $0(0.2)$ \\
\hline 6 & 1920 & 21 & 8 & 21 & $0(0.2)$ \\
\hline 7 & 1954 & 34 & 13 & 34 & $1(0.6)$ \\
\hline 8 & 1965 & 11 & 4 & 10 & $0(-0.4)$ \\
\hline 9 & 1975 & 10 & 4 & 10 & $0(0.4)$ \\
\hline 10 & 1991 & 16 & 6 & 16 & $1(0.6)$ \\
\hline 11 & 2002 & 11 & 4 & 10 & $-1(-0.8)$ \\
\hline 12 & 2009 & 7 & 3 & 8 & $1(1.0)$ \\
\hline 13 & 2010 & 1 & 0 & 0 & $0(0.4)$ \\
\hline 14 & 2013 & 3 & 1 & 3 & \\
\hline
\end{tabular}

$\Sigma \mid$ Error $\mid=6.8$

$\Sigma($ Error $)=0.0$

Table 3. Possible dates of the highest summer floods on the Danube River at Bratislava

\begin{tabular}{|c|c|c|c|}
\hline No. & $K$ & $K^{*} \Delta X$ & Date of the possible highest flood: $2013+K^{*} \Delta X$ \\
\hline 1 & 3 & 8 & 2021 \\
\hline 2 & 4 & 10 & 2023 \\
\hline 3 & 5 & 13 & 2026 \\
\hline 4 & 6 & 15 & 2029 \\
\hline 5 & 7 & 18 & 2031 \\
\hline
\end{tabular}

Table 4. Dates of the highest summer floods that occurred in the past on the Danube at Bratislava

\begin{tabular}{|c|c|c|c|c|c|}
\hline No. & $K$ & $K^{*} \Delta X$ & $\begin{array}{c}\text { Date that was calculated by } \\
\text { value of commen-surability: } \\
1883+K^{\star} \Delta X\end{array}$ & $\begin{array}{c}\text { Date from historical archives } \\
\text { (Pekárová et al. 2014) }\end{array}$ & Error \\
\hline 1 & -259 & -673 & 1210 & 1210 & 0 \\
\hline 2 & -207 & -538 & 1345 & 1344 & -1 \\
\hline 3 & -185 & -481 & 1402 & 1402 & 0 \\
\hline 4 & -160 & -416 & 1467 & 1466 & -1 \\
\hline 5 & -151 & -393 & 1490 & 1490 & 0 \\
\hline 6 & -148 & -385 & 1498 & 1499 & 1 \\
\hline 7 & -147 & -382 & 1501 & 1501 & 0 \\
\hline 8 & -137 & -356 & 1527 & 1526 & -1 \\
\hline 9 & -111 & -289 & 1594 & 1594 & 0 \\
\hline 10 & -82 & -213 & 1670 & 1670 & 0 \\
\hline 11 & -77 & -200 & 1683 & 1682 & -1 \\
\hline 12 & -37 & -96 & 1787 & 1787 & 0 \\
\hline
\end{tabular}

Table 5. The total number of time intervals of different duration indicating the date of the possible future highest summer flood on the Danube at Bratislava

\begin{tabular}{|c|c|c|c|c|c|}
\hline No. & Year & Number of time intervals & No. & Year & Number of time intervals \\
\hline 1 & 2019 & 8 & 8 & 2026 & 4 \\
\hline 2 & 2020 & 18 & 9 & 2027 & 4 \\
\hline 3 & 2021 & 8 & 10 & 2028 & 7 \\
\hline 4 & 2022 & 5 & 11 & 2029 & 7 \\
\hline 5 & 2023 & 7 & 12 & 2030 & 9 \\
\hline 6 & 2024 & 6 & 13 & 2031 & 5 \\
\hline 7 & 2025 & 9 & & & \\
\hline
\end{tabular}

\begin{tabular}{|c|c|c|c|c|}
\hline 1899 & 55 & 1954 & 55 & 2009 \\
\hline 21 & & 21 & & 21 \\
\hline 1920 & 55 & 1975 & 55 & $\mathbf{2 0 3 0}$ \\
\hline 34 & & 34 & & \\
\hline 1954 & 55 & 2009 & & \\
\hline
\end{tabular}

Fig. 3. The two-dimensional graph of commensurability of the highest summer floods on the Danube at Bratislava

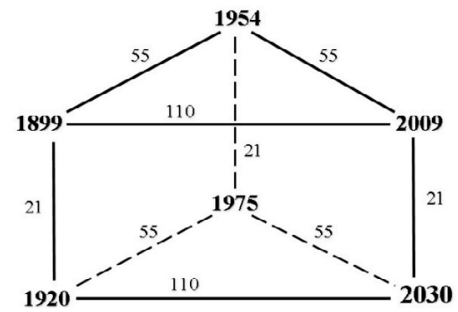

Fig. 4. The three-dimensional graph of commensurability of the highest summer floods on the Danube at Bratislava

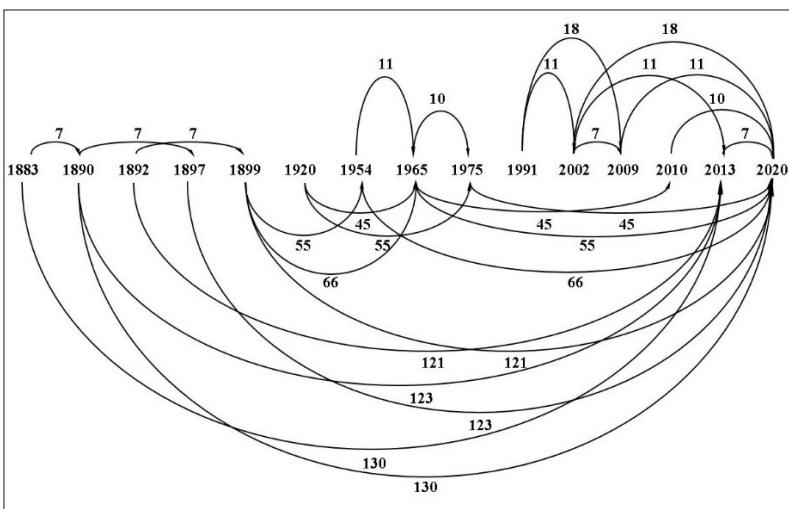

Fig. 5. Butterfly structure diagram of the highest summer floods on the Danube River at Bratislava (2020 is a forecast) 
Table 6. Time intervals that are indicating a possible high summer flood on the Danube at Bratislava in 2020

\begin{tabular}{|c|c|c|c|}
\hline No. & & terval, years & Number of repetitions \\
\hline 1 & 7 & $\begin{array}{r}1890-1883=\mathbf{7} \\
1897-1890=\mathbf{7} \\
1899-1892=\mathbf{7} \\
2009-2002=\mathbf{7} \\
\mathbf{2 0 2 0 - 2 0 1 3}=\mathbf{7}\end{array}$ & 4 \\
\hline 2 & 10 & $\begin{array}{c}1975-1965=10 \\
2020-2010=10\end{array}$ & 1 \\
\hline 3 & 11 & $\begin{array}{l}1965-1954=\mathbf{1 1} \\
2002-1991=\mathbf{1 1} \\
2013-2002=\mathbf{1 1} \\
\mathbf{2 0 2 0 - 2 0 0 9}=\mathbf{1 1}\end{array}$ & 3 \\
\hline 4 & 18 & $\begin{array}{l}2009-1991=18 \\
2020-2002=18\end{array}$ & 1 \\
\hline 5 & 45 & $\begin{array}{l}1965-1920=\mathbf{4 5} \\
2010-1965=\mathbf{4 5} \\
2020-1975=\mathbf{4 5}\end{array}$ & 2 \\
\hline 6 & 55 & $\begin{array}{l}1954-1899=\mathbf{5 5} \\
1975-1920=\mathbf{5 5} \\
2009-1954=\mathbf{5 5} \\
\mathbf{2 0 2 0}-\mathbf{1 9 6 5}=\mathbf{5 5}\end{array}$ & 3 \\
\hline 7 & 66 & $\begin{array}{l}1965-1899=\mathbf{6 6} \\
\mathbf{2 0 2 0}-\mathbf{1 9 5 4}=\mathbf{6 6}\end{array}$ & 1 \\
\hline 8 & 121 & $\begin{array}{l}2013-1892=\mathbf{1 2 1} \\
\mathbf{2 0 2 0}-\mathbf{1 8 9 9}=\mathbf{1 2 1}\end{array}$ & 1 \\
\hline 9 & 123 & $\begin{array}{l}2013-1890=123 \\
2020-1897=123\end{array}$ & 1 \\
\hline 10 & 130 & 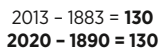 & 1 \\
\hline
\end{tabular}

Table 7. Time intervals that indicate a possible high summer flood on the Danube at Bratislava in 2025

\begin{tabular}{|c|c|c|c|}
\hline No. & \multicolumn{2}{|c|}{ Time interval, years } & Number of repetitions \\
\hline 1 & 16 & $\begin{array}{r}1899-1883=16 \\
1991-1975=16 \\
2025-2009=16\end{array}$ & 2 \\
\hline 2 & 23 & $\begin{array}{c}1920-1897=23 \\
2025-2002=23\end{array}$ & 1 \\
\hline 3 & 34 & $\begin{array}{l}1954-1920=\mathbf{3 4} \\
2009-1975=\mathbf{3 4} \\
\mathbf{2 0 2 5}-1991=\mathbf{3 4}\end{array}$ & 2 \\
\hline 4 & 71 & $\begin{array}{c}1954-1883=71 \\
1991-1920=71 \\
2025-1954=71\end{array}$ & 2 \\
\hline 5 & 105 & $\begin{array}{l}2002-1897=105 \\
2025-1920=105\end{array}$ & 1 \\
\hline 6 & 126 & $\begin{array}{l}2009-1883=126 \\
2025-1899=126\end{array}$ & 1 \\
\hline
\end{tabular}

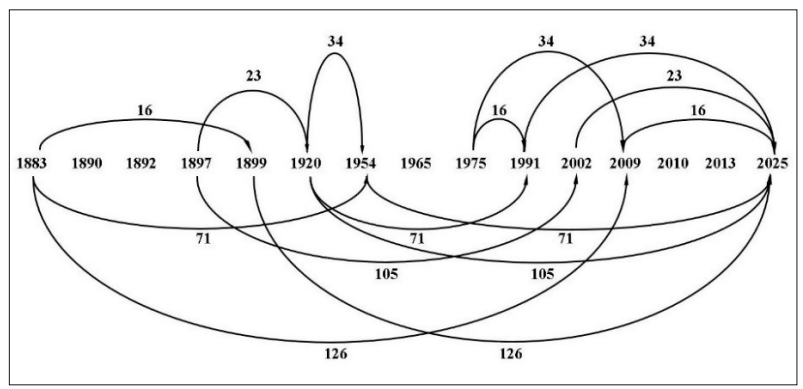

Fig. 6. Butterfly structure diagram of the highest summer floods on the Danube River at Bratislava (2025 is a forecast)
Table 8. Time intervals that indicate a possible high summer flood on the Danube at Bratislava in 2030

\begin{tabular}{|c|c|c|c|}
\hline No. & \multicolumn{2}{|c|}{ Time interval, years } & Number of repetitions \\
\hline 1 & 21 & $\begin{array}{c}1920-1899=\mathbf{2 1} \\
1975-1954=\mathbf{2 1} \\
\mathbf{2 0 3 0}-\mathbf{2 0 0 9}=\mathbf{2 1}\end{array}$ & 2 \\
\hline 2 & 28 & $\begin{array}{c}1920-1892=\mathbf{2 8} \\
2030-2002=\mathbf{2 8}\end{array}$ & 1 \\
\hline 3 & 55 & $\begin{array}{r}1954-1899=\mathbf{5 5} \\
1975-1920=\mathbf{5 5} \\
2009-1954=\mathbf{5 5} \\
\mathbf{2 0 3 0}-\mathbf{1 9 7 5}=\mathbf{5 5}\end{array}$ & 3 \\
\hline 4 & 76 & $\begin{array}{c}1975-1899=76 \\
2030-1954=76\end{array}$ & 1 \\
\hline 5 & 110 & $\begin{array}{l}2002-1892=110 \\
2009-1899=110 \\
2030-1920=110\end{array}$ & 2 \\
\hline
\end{tabular}

Table 9. Number of commensurability equations with three components for the dates of possible high summer floods on the Danube at Bratislava for the period 2019-2031

\begin{tabular}{|c|c|}
\hline Year & Number of equations \\
\hline 2019 & 4 \\
\hline 2020 & $\mathbf{9}$ \\
\hline 2021 & 4 \\
\hline 2022 & 3 \\
\hline 2023 & 4 \\
\hline 2024 & 4 \\
\hline 2025 & $\mathbf{5}$ \\
\hline 2026 & 2 \\
\hline 2027 & 3 \\
\hline 2028 & 4 \\
\hline 2029 & $\mathbf{5}$ \\
\hline 2030 & $\mathbf{5}$ \\
\hline 2031 & 4 \\
\hline
\end{tabular}

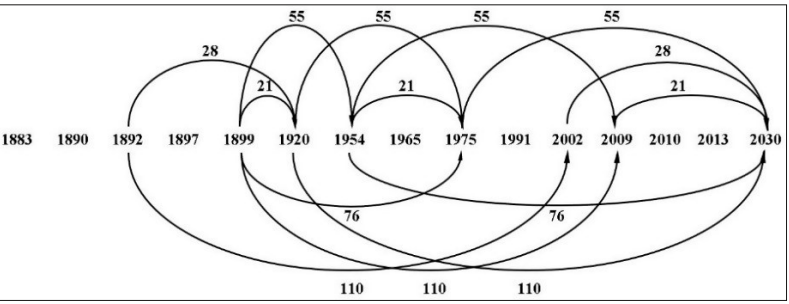

Fig. 7. Butterfly structure diagram of the highest summer floods on the Danube River at Bratislava (2030 is a forecast) 
Table 10. The commensurability equations with the three components for the dates of possible high summer floods on the Danube at Bratislava: 2020, 2025, 2029, and 2030

\begin{tabular}{|c|c|}
\hline Year & Equations \\
\hline & $1890+2013-1883=\mathbf{2 0 2 0}$ \\
& $1887+2013-1890=\mathbf{2 0 2 0}$ \\
& $1899+2013-1892=\mathbf{2 0 2 0}$ \\
& $1954+1965-1899=\mathbf{2 0 2 0}$ \\
& $1965+1975-1920=\mathbf{2 0 2 0}$ \\
& $1965+2009-1954=\mathbf{2 0 2 0}$ \\
& $1975+2010-1965=\mathbf{2 0 2 0}$ \\
& $2002+2009-1991=\mathbf{2 0 2 0}$ \\
& $2009+2013-2002=\mathbf{2 0 2 0}$ \\
\hline \multirow{5}{*}{2025} & $1954+1954-1883=\mathbf{2 0 2 5}$ \\
& $1899+2009-1883=\mathbf{2 0 2 5}$ \\
& $1920+2002-1897=\mathbf{2 0 2 5}$ \\
& $1954+1991-1920=\mathbf{2 0 2 5}$ \\
& $1991+2009-1975=\mathbf{2 0 2 5}$ \\
\hline \multirow{5}{*}{2029} & $1899+2013-1883=\mathbf{2 0 2 9}$ \\
& $1954+1965-1890=\mathbf{2 0 2 9}$ \\
& $2002+2002-1975=\mathbf{2 0 2 9}$ \\
& $1991+2013-1975=\mathbf{2 0 2 9}$ \\
& $2010+2010-1991=\mathbf{2 0 2 9}$ \\
\hline \multirow{6}{*}{2030} & $1920+2002-1892=\mathbf{2 0 3 0}$ \\
& $1954+1975-1899=\mathbf{2 0 3 0}$ \\
& $1920+2009-1899=\mathbf{2 0 3 0}$ \\
& $1975+1975-1920=\mathbf{2 0 3 0}$ \\
& $1975+2009-1954=\mathbf{2 0 3 0}$ \\
\hline
\end{tabular}

The value of commensurability $(\Delta \mathrm{X}=2.60$ years) can be used not only to predict the dates of the future highest summer floods, but also to determine the dates on which such floods occurred in the past on the Danube at Bratislava. The analysis shows that the dates of the highest summer floods from historical archives (Pekárová et al. 2014), which occurred before regular hydrometric observations, are closely consistent with the dates calculated using the value of commensurability (Table 4).

Forecasting results by the two-dimensional and three-dimensional graph of commensurability

Analyzing the date array of the highest summer floods, we found that the time intervals between individual floods were the same values: $1954-1899=55 ; 1975-1920=\mathbf{5 5}$; $2009-1954=55$ and $1920-1899=\mathbf{2 1}$; $1975-1954=\mathbf{2 1}$; and $1954-1920=\mathbf{3 4}$; $2009-1975=34$. This information supplies the two-dimensional graph of commensurability of the highest summer floods on the Danube at Bratislava (Fig. 3).

According to this graph, we can predict the following highest summer flood: vertically $2009+21=2030$ and horizontally $1975+$ $55=2030$. We also created the three-dimensional graph, which also shows that the highest summer flood can occur in 2030 (Fig. 4).

Forecasting results by the time intervals between floods that have occurred in the past

The time intervals between the individual highest summer floods that occurred in the past (1876-2013) were determined. We extrapolated these time intervals for the future to determine the dates of the highest summer floods that may occur in the coming years (2019-2036) (Table 5). We did not use dates of flood events before the regular monitoring because we are not sure that all the dates of high summer floods for the period 1210-1883 were identified in the historical archives.

The largest time span, namely 18 years, indicates that a high summer flood may occur in 2020 (Table 5, Fig. 5). In the past the time interval of 7 years has been repeated four times, time intervals of 11 and 55 years, three times, and time interval wof 45 years, twice (Table 6).

Nine intervals indicate a possible high summer flood in 2025 (Table 5, Fig. 6). Time intervals of 16,34 and 71 years have been repeated twice in the past (Table 7).

A high summer flood may also occur in 2030 (and nine intervals also indicate this) (Table 5, Fig. $7)$. In the past the time interval of 55 years has been repeated three times, and the time intervals of 21 and 110 years were repeated twice (Table 8).

\section{Forecasting results by the number of commensurability equations with the three components}

For the period 2019-2031, we have created all possible commensurability equations with three components, using the dates of the highest summer floods that have occurred in the past (1876-2018) on the Danube at Bratislava.

The largest number of equations (9) with three components was compiled for 2020 (Table 9). Consequently, the next high summer flood on the Danube at Bratislava may occur in 2020. Also, high summer floods are possible in 2025, 2029 and 2030. For these dates, 5 equations were compiled (Table 9).

The application of the commensurability method supported forecasts of the possible dates of high summer floods on the Danube at Bratislava. Although our results are tentative, it can be argued that they can be reliable. This confidence is reinforced by the application of the four commensurability forecasting methods, as well as by the retrospective analysis based on historical data. Strong consistency can be seen between historical flood dates that occurred before the beginning of regular hydrometric observations, and dates that were calculated by the values of commensurability. Thus, commensurability reflects the laws determining the occurrence of high floods as well as other natural disasters. The methodologi- cal approach of Weng Wen-Bo may be applicable to forecasting other dangerous natural phenomena, thus meriting further in-depth research.

Long-term forecasting of possible dangerous spring floods can be used to prevent and minimize the negative effects for the population and economy.

\section{CONCLUSION}

Weng Wen-Bo's methodology is perhaps the only one that supports long-term forecasting of various natural disasters, including floods, with the minimum array of input information. After calculating the commensurability value for the highest summer historical floods, we forecast possible high summer floods on the Danube at Bratislava in the coming years: 2021, 2023 , 2026, 2029 and 2031. Retrospective analysis of the calculated commensurability value confirmed the dates of the highest summer floods that occurred in the past.

The two- and three-dimensional graphs of the commensurability clearly indicate that a high summer flood may occur in 2030 on the Danube at Bratislava. The method of forecasting by the time intervals between the highest summer historical floods shows that high summer floods may possibly occur in 2020, 2025 and 2030. The forecasting method using the number of commensurability equations with three components shows the dates of possible high floods in 2020, 2025, 2029, and 2030.

So, the majority of commensurability methods indicate to us that the next series of high summer floods on the Danube at Bratislava may occur in 2020, 2025, and 2030.

\section{ACKNOWLEDGMENTS}

The investigation was carried out in the framework of the Slovak-Ukrainian project No. 11 "Impacts of global climate changes on water resources in Ukraine estimated by variability of river discharges and hydrograph components" in accordance with the agreement on cooperation between the National Academy of Sciences of Ukraine and the Slovak Academy of Sciences, 2016-2019.

\section{REFERENCES}

- Blöschl G., Szolgay J., Parajka J., Kohnová S. Miklánek P., 2016, Thematic issue on floods in the Danube basin - processes, patterns, predictions, Journal of Hydrology and Hydromechanics, 64 (4), 301-303, DOI: 10.1515/johh2016-0043 
- Böhm O., Wetzel K.-F., 2006, Flood history of the Danube tributaries Lech and Isar in the Alpine foreland of Germany, Hydrological Sciences Journal, 51 (50), 784-798, DOI: 10.1623/hysj.51.5.784

- Gorbachova L., 2015, The intra-annual streamflow distribution of Ukrainian rivers in different phases of long-term cyclical fluctuations, Energetika, 61 (2), 71-80, DOI: 10.6001/energetika.v61i2.3134

- Gorbachova L., Khrystyuk B., 2014, Hydro-genetic methods of the analysis of the average annual runoff in the Danube basin, [in:] Proceeding of XXVI Conference of the Danubian Countries on Hydrological Forecasting and Hydrological Bases of Water Management. Bridging the sciences crossing borders, 22-24 September 2014, Deggendorf, Germany, 71-74

- Hongyan L., Yuxin W., Xiubin L., 2011, Mechanism and forecasting methods for severe droughts and floods in Songhua River basin in China, Chinese Geographical Science, 21 (5), 531-542, DOI: 10.1007/s11769-011-0492-y

- Khrystyuk B., 2013, The technique of the forecasting of the characteristic ten-day water (in Ukrainian), Proceeding of UHMI, 265, 15-22

- Khrystyuk B., 2014, The forecasting of the mean monthly water levels of the Danube River on the water gauge Reni, [in:] Proceeding of XXVI Conference of the Danubian Countries on Hydrological Forecasting and Hydrological Bases of Water Management. Bridging the sciences crossing borders, 22-24 September 2014, Deggendorf, Germany, 153-160.

- Komma J., Nester T., Salinas J., Blöschl G., 2017, Stochastic rainfall-runoff modelling to evaluate the spatial concurrence of the runoff of Inn tributaries, [in:] Proceeding of XXVII

Conference of the Danubian Countries on Hydrological Forecasting and Hydrological Bases of Water Management, 26-28 September 2017, Golden Sands, Bulgaria, 356 pp.

- Meissner D., Klein B., Ionita M., 2017, Development of a monthly to seasonal forecast framework tailored to inland waterway transport in central Europe, Hydrology and Earth System Sciences, 21 (12), 6401-6423, DOI: 10.5194/hess-21-6401-2017

- Pekárová P., Halmová D., Bačová Mitková V., Miklánek P., Pekár J., Škoda P., 2013, Historic flood marks and flood frequency analysis of the Danube River at Bratislava, Slovakia, Journal of Hydrology and Hydromechanics, 61 (4), 326-333, DOI: 10.2478/johh-2013-0041

- Pekárová P., Miklánek P., Melo M., Halmová D., Pekár J., Bačová Mitková V., 2014, Flood marks along the Danube River between Passau and Bratislava, edition 1, Bratislava, Veda, 103 pp.

- Pekárová P., Miklánek P., Pekár J., 2006, Longterm trends and runoff fluctuations of European rivers, [in:] Climate variability and change hydrological impacts. Proceedings of the fifth FRIEND World Conference held at Havana, Cuba, November 2006, IAHS Publications, 308, 520-525

- Pekárová P., Miklánek P., Pekár J., 2007, Longterm Danube monthly discharge prognosis for the Bratislava station using stochastic models, Meteorologický časopis, 10, 211-218

- Pekárová P., Onderka M., Pekár J., Miklánek P., Halmová D., Škoda P., Bačová Mitková V., 2008, Hydrological scenarios for the Danube River at Bratislava, Ostrava; KEY Publishing, 159 pp.

- Peng Z., Zhang L., Yin J., Wang H., 2017, Commensurability-based flood forecasting in Northeastern China, Polish Journal of Environmental Studies, 26 (6), 2689-2702, DOI: 10.15244/pjoes/73859
- Rohr C., 2013, Floods of the Upper Danube River and its tributaries and their impact on urban economies (c. 1350-1600): The examples of the towns of Krems/Stein and Wels (Austria), Environment and History, 19 (2), 133-148, DOI: 10.3197/096734013X136420825 68534

- Romanescu G., Stoleriu C.C., 2017, Exceptional floods in the Prut basin, Romania, in the context of heavy rains in the summer of 2010, Natural Hazards and Earth System Sciences, 17 (3), 381-396, DOI: 10.5194/nhess-17-381-2017

- Sonnlechner C., Hohensinner S, Haidvogl G., 2013, Floods, fights and a fluid river: the Viennese Danube in the sixteenth century, Water History, 5 (2), 173-194, DOI 10.1007/s12685013-0077-z

- Su Y.J., Hu H., 2015, Application of commensurability in earthquake prediction, International Journal of Geosciences, 6 (6), 619-624, DOI: 10.4236/ijg.2015.66049

- Tenk A., Dávid L., 2015, Geographical and GIS analysis of the great flood of 1838 in Pest-Buda, Geographia Technica, 10 (1), 77-89

- Weng W.B., 1984, Basis of prediction theory, (in Chinese), Petroleum Industry Press, $45 \mathrm{pp}$.

- WMO, 2009, Guide to hydrological practices. Volume II. Management of water resources and application of hydrological practices, $6^{\text {th }}$ edition, WMO-No. 168, World Meteorological Organization, Geneva, available at: http:// www.wmo.int/pages/prog/hwrp/publications/guide/english/168_Vol_II_en.pdf (data access 27.11.2019)

- Zabolotnia T., Gorbachova L., Khrystyuk B., 2019, Estimation of the long-term cyclical fluctuations of snow-rain floods in the Danube basin within Ukraine, Meteorology Hydrology and Water Management. Research and Operational Applications, 7 (2), 3-11, DOI: 10.26491/ mhwm//99752 


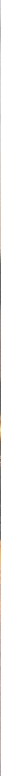

